DOI 10.37882/2223-2982.2021.11.38

\title{
МЕТОДЫ КИТАЙСКОГО ПЕРЕВОДА ПО СЛОВАМ РУССКИХ СОВРЕМЕННЫХ ЛИТЕРАТУРНЫХ ПРОИЗВЕДЕНИЙ
}

\section{CHINESE TRANSLATION METHODS OF RUSSIAN CONTEMPORARY LITERARY WORKS}

Chen Peipei

Summary: Russian contemporary literary works serve as a medium for cultural exchanges, and translation is a transformation between linguistic symbols, the transmission of meaning and communication between cultures. In translation, words are the basic unit of a sentence, an accurate understanding of words is a prerequisite for the translation of a work. This article examines concept and importance of translation, analyzes the methods of Chinese translation by words, such as the translation of proper names, transposition of words from one part of speech to another, the reception of lexical additions and the reception of omission, commenting and phraseologism and a fixed phrase. Translation according to words is a king of creative linguistic activity, it is an art, not a mechanical change of language. They contain both theoretical elements and the most direct guiding effect in practice.

Keywords: translation according to words, Chinese methods, Russian works, literature.

\author{
Чэнь Пэйпэй \\ аспирант, старший преподаватель, \\ Шихецзыский университет \\ chenpeipei0112@126.com
}

Аннотация: Русские современные литературные произведения - служат средой для культурных обменов, а перевод - это трансформация между лингвистическими символами, передачей смысла и общением между культурами. В переводческой деятельности слова являются основной единицей предложения, точное понимание слов является предпосылкой перевода произведения. В данной статье рассматриваются понятие и важность перевода, анализируются методы китайских переводов по словам, как перевод имен собственных, транспозиция слов из одной части речи в другую, приём лексических добавлений и приём опущения, комментирование, фразеологизация и фиксированное словосочетание. Перевод по словам - это своего рода творческая языковая деятельность, это искусство, а не механическая смена языка. Он содержит как теоретические элементы, так и самый непосредственный руководящий эффект на практике.

Ключевые слова: перевод по словам, китайские методы, русские произведения, литература.
$\mathrm{B}$ последние годы китайско-российские отношения становятся всё более тесными, обе страны имеют обмены и взаимную помощь в различных областях. В дополнение к обменам в области экономики и технологий нельза обойтись и без культурных обменов. Культура нации должна развиваться, помимо того, что она опирается на собственные стили, она должна впитывать чужую культуру. Перевод обеспечивает эффектифное средство восприятия различных культур [2, с. 15-19].

Перевод - это мост между разными культурами, без перевода невозможно достичь общения и обучения между разными культурами. В настоящее время, Китай добился значительных успехов в изучении теории перевода - переводоведение приобрело статус независимой дисциплины и процветает благодаря усилиям каждого учёного.

Перевод - это акт преобразования информации на одном языке в информацию на другом языке на основе точных и беспрепятственных утверждений. Это, своего рода, символическая трансформация между двуми языками, а не трансформация между двумя культурами, представленная этими языками.
Литературные произведения, несомненно, служат средой для культурных обменов, что не только предоставляет обычным читателям платформу для понимания современной русской литературы, но и добавляет новые свидетельства для отечественных учёных для изучения современных русских писателей и их произведений.

Самая большая разница между литературными произведениями и другими устными произведениями заключается в том, что они выполняют эстетические или поэтические функции. Основной целью любого литературного произведения является создание художественного образа и достижение определённого эстетического эффекта. Таким образом, основная задача литературного перевода - использовать переведенный язык для создания словесного продукта, который может оказывать литературное эстетическое воздействие на целевую аудиторию [2, с. 4].

Литература - это художественное воплощение языка, поэтому язык литературных произведений предъявляет эстетические требования. Переводчик должен учитывать точный перевод оригинального текста и понимание первоначального значения слова в переводе. 
Перевод должен быть основой на достоверном оригинальном тексте, благодаря тонкому обращение переводчика будет передаваться оригинальная рифма и воспроизводиться точное содержание на другом языке и сохраняться его художественная привлекательность. Тем не менее, в процессе развития, из-за географии, истории, религии и других факторов, этническое поведение, речевые привычки и выражения значительно различаются. Переводчик должен перевести два языка друг на друга в сочетании с конкретным переводом целевого читателя. Здесь мы должны выбрать конкретную стратегию перевода и метод перевода в нужное время.

Так называемые методы перевода - это лишь некоторые из закономерностей, полученных при сравнении разных языков. Поэтому перевод - это своего рода творческая языковая деятельность, это искусство, а не механическая смена языка. Мы должны противопоставлять пословной перевод и случайный перевод, нужно противостоять буквальным рабам, но и превратить перевод в переписывание или рассказ [1, с. 1].

В переводческой деятельности слова являются основной единицей предложения, точное понимание слов является предпосылкой перевода произведения. Поэтому в переводе нельзя рассматривать языковой феномен изолированно, но следует учитывать соответствующие средства выражения и использовать соответствующие методы для перевода в соответствии с конкретной ситуацией.

\section{1. Перево и имен собственных}

Поскольку история и обычаи общественного развития в Китае и России различны, некоторые слова на русском языке, которые выражают специфичные для русского языка вещи, не могут быть выражены на китайском языке. Обычно в переводе используются три варианта.

По произношению: Виктория (维多利亚), Антон (安 东), Москва (莫斯科); по значению: Орёл (鹰城, Детский сад (幼儿园); по произношению и значению: Ново-Клюквино (新克柳克维诺) - префикс «Ново» означает новый, а «Клюквино» относится к названию колхоза, поэтому первая половина переведена по значению, а вторая по произношению.

\section{2. Транспозишия слов из одной части речи в $\triangle$ ругую}

Из-за различных языковых привычек выражения русского и китайского языков при переводе часто требуется изменить, то есть существительные не нужно переводить в существительные, а глаголы не нужно переводить в глаголы. Если каждое слово в исходном тексте копируется механически, это иногда разрушает правила языка, влияя на выражение значение и плавность перевода [1, с. 126]. Чтобы удовлетворить читательские привычки чтения, переводчикам часто нужно перевести одну часть слова в другую.

- Очевидно, заключенному необходимо что-то лежащее вне его паскудной жизни. Вне зоны и срока. Вне его самого. [6] (看来，四犯需要某种脱离于龂龊日子，脱离监 狱和刑期，脱离他自己的东西。) 《вне» в этом предложении является предлогом и имеет значение «за, снаружи», что переводится в глагол «разъединение», делает значение первоначального значения более ясным.

- А что, ей ведь трибунал не страшен. [6] (它又不怕上 法庭。 ) «страшен» - это короткая форма прилагательного «страшный», который используется здесь как «страх».

- Доматые стены казались особенно неподвижнымu. [6] (木板墙一动不动地站着。) 《неподвижный»- это прилагательное, но в переводе слово используется как наречие «неподвижно», что делает перевод более в соответствии с привычным выражением китайского языка.

- Десять раз туда и сюда, равнение на столб, шагом... - стариина выдержал паузу, - марш! [7] (十次来 回，向柱子看齐，齐步......司务长停顿了一下，“走! ”) Слова «равнение» и «марш» в предложении являются существительными в русском языке, они означают «выравнивание» и «темп». Они переводятся в глаголы во время перевода и переводятся как «быть выровненными», «идти». Перевод глаголов может воспроизвести тон тогдашнего старшина, что делает содержание статьи более актуальным.

\section{3. Приём лексических Аобавлений и приём опушения}

\section{1 Приём лексических Аобавлений}

В дополнение к некоторым значением русского и китайского языков, большинство из них различаются по объёму, грамматическим функциям, риторическим характеристикам и привычкам использования [1,с. 31]. Поэтому, чтобы точно выразить смысл исходного текста, необходимо добавить некоторые слова, фразы и даже предложения, которые буквально не присутствуют в исходном тексте. Добавленные слова - это в основном глаголы, личные местоимения, наречия и некоторые пояснительные слова. Но слова должны быть верны оригиналу

\section{- Куда ты собрался? [12] (你要上哪儿去?)}

В исходном тексте используется только глагол «собрался», в сочетании с контекстом известно, что здесь следует добавить глагол «идти», оригинальный текст 
переводится как «куда ты собрался идти?».

- Om страха опустил глаза и шел сутулясь, боязливо косясь на сонные дорожные столбы. [12] (由于恐惧, 他 奇拉着眼皮，弓着腰向前走去，还一边对着杵在路旁电 线杆翻白眼。)

Подлежащий исключен из исходного текст, но для того, чтобы перевод соответствовал китайским привычкам выражения, здесь должно быть дополнено личное местоимение «он»

- Клеенкой свежей пахнет. [12] (空气中飘着刚刷的油 漆味儿。)

В оригинальном тексте используется без названия на русском языке. В переводе может быть добавлено соответствующее наречие «в воздухе» в зависимости от контекста.

\section{2 Приём опушения}

В практике перевода иногда необходимо опускать отдельные слова исходного текста, в противном случае написание вызывает смущение, не в соответствии с привычками выражения перевода, а иногда даже влияет на точное выражение исходного намерения. Сокращение слов, чтобы лучше понять смысл.

- А железную птицу Нюра приняла обыкновенный самолет "У-2», а перекошенным клювом показался ей неподвижно застывший воздушный винт. [7] (纽拉把一 架普通的苏军乌-2飞机误当作铁灰色的鸟，而她以为的 歪斜鸟喙其实是停滞不动的螺旋桨。) 《неподвижно» это наречие, означающее «неподвижный, статичный», а «застывший» - глагол прошедшего времени «застыть», означающий «застой». Поскольку значения этих двух одинаковые, они могут быть переведены в «停滞不动》, которые могут сделать предложение кратким и ясным, а использование китайских фраз из четырёх слов может наращивать гармоничную красоту переведенной фонологии, поэтому высказывание становится лаконичным и ярким.

- Хотелось лечь и ни о чем не думать, заснуть летаргическим сном. [6] (她真想什么都不用考虑, 睡个昏天黑 地。) «заснуть» означает «спать, засыпать», «летаргический сон» означает сонливость, они на самом деле представляют собой только значение слов, то есть «спящее», поэтому нет необходимости переводить отдельно.

- В ней много цинизма, притворства, рисовки. [6] (信 中有很多无耻、虚假、做作的言语。)

В соответствии с внутренним значением исходного текста плюс слово «речь», перевод более понятен с пер- вого взгляда, а также соответствует языковым нормам китайского языка.

\section{4. Комментирование}

Из-за множества различий между русским и китайским языком и культурой некоторые слова с собой культурной спецификой на русском языке не могут быть заменены эквивалентными словами на китайском языке, что создаёт вакансию в значении слов. В этом случае русский перевод часто использует комментирование. Оно обычно может использоваться для дополнения соответствующей информации, такой как справочная информация, происхождение слов и т.д. чтобы читатель мог быстро понять.

\section{1 Внеэквивалентное явление}

- Каждый вечер мама играет с Викторией в «Чёрного Петра» на орешки арахиса. [4] (每天晚上她的妈妈都和维 多利亚完“黑彼得”- 的游戏，并以花生米做赌注。)

捷克传统游戏(Чехия традиционные игры).

- Уж я бы подписался на эту маршифаль! [6] (我要是 还能点上一份马西法塔尔就好了!)

2 一种食物，指带有杏仁泥的鲻鱼。(Это пища， палец кефаль с миндальной грязью).

- Фетровые боты $\mathbf{l}^{3}$ утопали в грязи. [6] (高勒毡靴陷 入了泥泞。)

3 一种以羊毛或驼毛擀制而成的靴子，保暖耐磨损， 一般多在隆冬时节穿用。(Сапоги из шерсти или верблюжьей шерсти, которые тёплые и износостойкие, и их обычно носят зимой).

\section{2 Прешехентный феномен}

- Клянусь Гринвичским меридианом ${ }^{4}$, я ешё не слышал столь приятного слова, как её «друг». [8] (我用格林威治 子午线发誓，我还没听说过，像是“她的朋友”这么悦耳 的话语。)

Гринвичский меридиан выразил искренность главного героя, цель состоит в том, чтобы повысить авторитет своих слов и убедить другую сторону высказать своё мнение, имеется убеждающая функция. Для того, чтобы соответствовать китайским привычкам чтения, лучше перевести на него клянусь Богу.

- Такая тихая старушка! кошке нахвост наступит ${ }^{5}$ извиниться! [10] (这本是多么安静的老太太啊! 猫的屁股 摸不得啊，快道㴚！）

В языковом выражении важно правильно выражать свои мысли, а способ выражения идей важнее и может играть роль активной атмосферы образа. Применимо к 
китайскому «кошке не хвост наступит» языку, например «Я не могу прикасаться к ягодицам тигра», читателю легко понять, нет никакой двусмысленности, здесь имеется игровая функция.

- Шишин зло, угрюмо на высокого, красивого Бобрыкина смотрел замерзшими глазами, слезясь и щурясь, на Бобрыкина, женатого на Тане, похожего в пальто на Ланового ${ }^{6}$. [12] (希辛用冷冰冰的眼神恶狠狠又有些有闷地盯 着高大帅气，还娶了塔尼亚的鲍布雷金，他穿着大衣， 看起来就像兰诺威。)

Лановой был известным актёром в советское время, здесь Бобрыкин, описывает своего красавца, имеется номинативная функция.

- И можем поверить шутливой фразе Гумилева: «На Венере, ах, на Венере у деревьев синие листья». Но ведь Россия - не Венера. Это же наша страна, наша родина. [9]（我们可以相信古米廖夫的玩笑话，“在金星上，啊， 在金星上有蓝色的叶子”。但是俄罗斯不是金星, 是我们 的祖国。)

«Синие листья на Венере» - по словам Гумилёва «на далекой Венере», Венера обычно говорит о стремлении русского народа к неизвестному. Мы ничего не знаем о флоре и фауне на Венере. Но, казалось бы, шутливый стих Гумилёва «На Венере у деревьев синие листья», но мы можем в это поверить. Здесь имеется парольная функция.

\section{5. фразеологизация и фиксированное словосочетание}

Фразеологизм - это кристаллизация языка, характеризующаяся яркими образами, богатыми воображением, глубоким смыслом и лаконичным языком. Фиксированное словосочетание относится к идиомам с относительно фиксированной структурой, это одно из сложных языковых явлений и обычный метод выражения для долгосрочного развития иностранных языков.

- Брешет собака. А я говорю. А ты свою варежку закрой, да, и не раскрывай, пока я тебе не дам разрешения. Понял? Не то я тебе на язык наступлю. [7] ("我没有瞎 扯。狗才瞎扯呢。闭上你的嘴吧，是的，干万不要张开 嘴，我暂且没允许你说话。明白吗? 否则我会用自己的 方式让你住嘴。"）

Это предложение, дословно переведенное как «иначе я наступлю на твой язык», но фактический смысл таков: «используйте насилие, чтобы заставить его заткнуться». В переводе помимо выражения смысла, мы должны поддерживать яркий образ, соответствующую метафору, отражать богатые эффекты ассоциации и национальные особенности.
- Там лестница у них такая скользкая, что можно шею запросто себе свернуть, ни разу чем-нибудь специальным не посыплют - сидят и ждут, пока я щею у них себе сверну. [12] (他们的楼梯那么滑，会把我摔成残废 的，人们从来也不往那里撒点什么，我还没摔得头破血 流的时候，他们就在那坐着，等着。) 《свернуть себе шею» изначально означало «открутить шею». Русские считали, что голова человека очень важна, шея тесно связана с головой, также очень серьезно сломать шею. Поэтому фраза расширена до тяжело ранен и сломлен по инвалидности.

- В метро особенно опасно, возле турникетов - того 2ляди возьмут и mpecнym. [12] (他觉得从旋转门]进地铁站 非常危险，要当心!会被门夹住，又要当心り上的玻璃会 裂。)

В фиксированном совпадении китайское значение «глядеть» означает «смотреть». В древних войнах часто нужно быть осторожным везде и смотреть вокруг, люди часто говорят «смотри», «того» здесь означает «тот или то», что определяется как «будь осторожен и осторожен».

- Что, Парамонов, - заорал сержант, - яйца мешают?! [6] ("怎么了，帕拉蒙诺夫，"军士大喊起来，“又然天尤 $\Delta$ 呢? !") «яйца мешают» - это фиксированная фраза, означающая оправдываться за неудачу, делать неправильные вещи, не находить причины у себя, всегда обвинять внешние факторы. Следовательно, это переводится как «роптать на небо и винить людей».

- Но Теплый, как всегда во время раздеванья-одеванья, рассеян, страшно рассеян, ему не до застежек, не до каштанов. [11] (但是焦普雷穿衣、脱衣时总是心不在焉的， 压根儿没把心思放在扣扣子和穿裤子上。） 《кому не до кого-чего» это означающее «где нет усилий, нет интереса». Чтобы показать рассеянность маленького мальчика во время перевода, можно перевести как «вообще не обратить внимание на пуговицы и штаны».

- Понятное дело, у Бегорского денег-куры не клюют, а клуб-то уже на последнем издыхании, старики бегут от него, как черт от ладана, даже персонал начал увольняться. [5] (显然别加尔斯基腰缠万贯，但俱乐部已经奄 奄一息，老人们就像躲地狱魔鬼一样远离它，甚至工作 人员也开始辞职。) «у кого денег - куры не клюют» дословно переводится как "у кого-то больше денег», как курица не покончена с рисом, означает больше денег не добить, можно перевести на богатых.

Язык является продуктом труда людей и постепенно формируется в ответ на потребности человеческого взаимодействия. Тем не менее, каждый язык имеет свои особенности, эти характеристики тесно связано с историей, традициями, обычаями и привычками нации, 
создавшей язык. У каждого языка есть свои законы произношения, слова и предложения. При переводе необходимо выбирать соответствующие средства, сравнивая словарный запас, грамматику и риторику на разных языках, так называемые методы перевода - это лишь некоторые из закономерностей, полученных при сравнении разных языков.

Переводчик использует методы перевода для решения проблем в процессе перевода, и в то время обогащает содержание методов перевода примерами, чтобы сделать их совершенными. Соответственно, переводчик также может обобщить новые методы перевода в практике непрерывного перевода и обогатить теорию перевода.

Значение перевода состоит в том, чтобы понимать язык и культуру разных стран, а также общаться и распространять культуру в форме слов. Однако, из-за различий в культурных и языковых привычках между двумя странами, неизбежно возникают некоторые трудности в процессе перевода: стилевое изображение текста в готовых работах должно быть сохранено и передано как можно более полно, а характеристик этого текста должны быть воспроизведены, чтобы читатели получили те же или похожие чувства. На основе полного выражения исходного текста использование методов перевода делает его более соответствующим для китайских выражений.

Между Китаем и Россией существуют культурные различия, поэтому если во время перевода не хватает понимания русской культуры и переводится буквальное значение истории, она может не передать истинное значение или даже неверно истолковать значение оригинального текста, поэтому культурные различия в переводческой работе - одна из трудностей перевода. Следовательно, в процессе перевода требования автора более строгие, они не только требуют от автора хорошего понимания русского и китайского языков, но и китайской русской культуры.

ЛИТЕРАТУРА

1. 蔡毅.俄译汉教程[M].外语教学与研究出版社, 1981. Цай И. Курс русско-китайского перевода. М.: Издательство по преподаванию и исследованию иностранных языков, 1981.

2. 杨仕章. 俄汉翻译基础教程[M].高等教育出版社,2010. Ян Шичжан. Базовое учебное пособие по русско-китайскому переводу. М.: Издательство высшего образования, 2010.

3. 杨仕章.略论翻译与文化的关系[]].解放军外国语学院学报,2001.№2.15-19. Ян Шичжан. 0 взаимоотношениях между преводом и культурой[текст]. Журнал университета иностранных языков НОАК. 2001.№2.15-19.

4. Бабушка с крылышками [Электронный ресурс] - URL http://kidreader.ru/author/2450

5. Жизнь после жизни [Электронный ресурс] - URL http://reshetoria.ru/literaturnye_hroniki/knigosfera/news3047.php

6. Зона [Электронный ресурс] - URL https://ru.wikipedia.org/wiki/Зона._Записки_надзирателя

7. Лицо неприкосновенное [Электронный ресурс] - URL https://reedcafe.ru/summary/priklyucheniya-soldata-ivana-chonkina

8. Маленькие люди [Электронный ресурс] - URL: https://libcat.ru/knigi/proza/304664-artur-mejchen-malenkie-lyudi.html

9. На Венере синие листья [Электронный ресурс] - URL http://cts.gdufs.edu.cn

10. Приключения жёлтого чемоданчика [Электронный ресурc] - URL https://readly.ru/book/11486/

11. Тётя Мотя [Электронный ресурc] - URL https://readly.ru/book/53687/

12. Убить Бобрыкина [Электронный ресурс] - URL https://www.spb.kp.ru/daily/26749/3778758/0лег Жданов, «Убить Бобрыкина»: Свежее возвращение.

() Чэнь Пэйпэй (chenpeipei0112@126.com).

Журнал «Современная наука: актуальные проблемы теории и практики» 